\title{
Strategy evolution in the total synthesis of $(-)$-leiodermatolide
}

\author{
Ian Paterson ${ }^{[\mathrm{a}]}$ and Simon Williams ${ }^{[\mathrm{a}]}$ \\ Dedicated to K. C. Nicolaou and Stuart Schreiber on the occasion of their receipt of the 2016 Wolf Prize
}

\begin{abstract}
This review highlights the various challenges overcome during our recent synthetic campaign towards (-)leiodermatolide, a potent cytotoxic and antimitotic macrolide isolated from the marine sponge Leiodermatium $\mathrm{sp}$. This structurally unprecedented macrocyclic chemotype represents a promising lead for anticancer drug discovery, provided a sustainable supply can be realised by an efficient chemical synthesis. Faced with the stereochemical ambiguities arising from our structural assignment work, a
\end{abstract}

flexible and modular synthetic strategy was adopted for the construction of various key fragments, as a prelude to the controlled assembly of the two diene moieties. Installation of the nine stereocentres was achieved by the strategic use of boron-mediated aldol reactions of chiral ketone building blocks. Following the exploratory construction of the macrocyclic core, we revised our strategy to circumvent some problematic steps, enabling a highly convergent total synthesis of (-)-leiodermatolide.

Keywords: natural products • marine macrolides $\bullet$ anticancer $\bullet$ stereocontrolled synthesis $\bullet$ macrocycles

\section{Introduction}

Marine organisms afford a valuable reservoir of structurally diverse, bioactive natural products for the discovery and development of new cancer chemotherapeutic agents. ${ }^{[1]}$ Several approved drugs based on novel chemotypes, eliciting exceptionally potent antitumour activity, have originated from this focused bioprospecting in the world's oceans. Prominent examples are Yondelis $^{\circledR}$, Halaven ${ }^{\circledR}$ (a simplified version of the halichondrin family of macrolides) and Adcetris ${ }^{\circledR}$, one of the first successful antibody-drug conjugates (ADCs), while many other marine drug candidates have progressed into clinical trials. ${ }^{[2]}$

However, the potent biological activity exhibited by the most promising of these drug leads is often mirrored by their extremely scarce natural supply, such that realising a practical chemical synthesis and associated SAR studies are essential steps to opening up the bottleneck to any clinical development. ${ }^{[3]}$ A compelling example here is the cytotoxic marine peptide dolastatin 10, first isolated by Pettit in low milligram quantities from hundreds of kilograms of the sea hare Dolabella auricularia ${ }^{[4]}$ which evolved into auristatin $\mathrm{E}$ as the potent microtubule-disrupting payload featured in Adcetris ${ }^{\circledR}$ along with many other ADCs currently in clinical trials. ${ }^{[5]}$

Over the past two decades, we have enjoyed a rewarding association with the marine natural product division of the Harbor Branch Oceanographic Institute at Florida Atlantic University. This collaboration arose from our synthetic interest in discodermolide (1, Figure $1),{ }^{[6]}$ a novel anticancer polyketide first isolated in 1990 from the lithistid sponge Discodermia dissoluta by
Gunasekera and co-workers. ${ }^{[7]}$ Discodermolide was later discovered to share a similar microtubulestabilising mechanism of action to taxol, with a common binding site on $\beta$-tubulin, whilst exhibiting potent antiproliferative activity against drug-resistant cancer cell lines and inhibiting the growth of solid tumours in animal models. Following an impressive resupply campaign, a large-scale synthesis of discodermolide was achieved by Novartis process chemists, relying on the prior art of the Smith group ${ }^{[8]}$ and ourselves, ${ }^{[6]}$ enabling this promising cancer chemotherapeutic agent to enter clinical trials. $^{[9]}$

In 2003, toxicity issues led to discodermolide being dropped from further clinical development. Whilst around that time, the Harbor Branch team of Wright isolated a macrocyclic polyketide from a deep-water lithistid sponge of the family Corallistidae, and discovered that it was also a promising microtubulestabilising agent and generally demonstrated superior antiproliferative activity. ${ }^{[10]}$ This transpired to be dictyostatin, a 22-membered macrolide previously reported by the Pettit group ${ }^{[11]}$ and, although structurally related to discodermolide, the $3 \mathrm{D}$ stereostructure was

[a] I. Paterson, S. Williams

University Chemical Laboratory, University of Cambridge, Lensfield Road, Cambridge CB2 1EW, UK phone: $+44(0) 1223336407$

fax: $+44(0) 1223336362$

e-mail: ip100@cam.ac.uk 
Ian Paterson received his $\mathrm{BSc}$ in Chemistry in 1976 from St. Andrews University. In 1979, he obtained his PhD from Cambridge University, working with Professor lan Fleming After a one-year stay as a NATO Postdoctoral Research Fellow with Professor Gilbert Stork at Columbia University, New York, he joined the faculty at University College London. In 1983, he moved back to Cambridge, where he is Professor of Organic Chemistry and a Fellow of Jesus

College. His research interests are centred on the development of novel synthetic methods for the control of stereochemistry and the total synthesis of bioactive natural products, particularly anticancer agents.

Simon Williams received his $\mathrm{BA}$ and MSci degrees in 2011 from the University of Cambridge. He stayed in Cambridge to study with Professor lan Paterson and was part of the team that achieved the total synthesis of leiodermatolide. He completed his PhD in 2015 and is currently a research associate in the Paterson group working on natural product total synthesis.

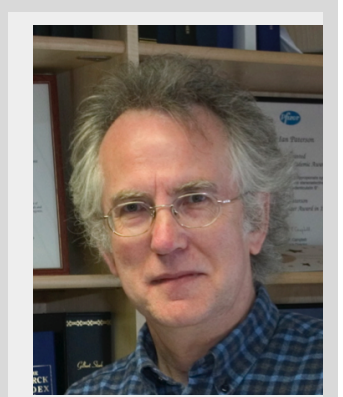

not fully assigned. Using a combination of detailed NMR analysis and molecular modelling, we were able to determine the complete stereochemistry of dictyostatin as shown in $\mathbf{2}$. Soon after reporting this structural assignment, ${ }^{[12]}$ it was validated by the independent total syntheses from ourselves ${ }^{[13]}$ and that of the Curran group. ${ }^{[14]}$ The resulting sustainable supply afforded by chemical synthesis then opened up extensive biological studies on dictyostatin, along with the design and synthesis of various analogs including the highly potent hybrid 3 with discodermolide. ${ }^{[15]}$

Following these productive collaborations, we next joined forces with Amy Wright and her colleagues to determine the full $3 \mathrm{D}$ structure of leiodermatolide, ${ }^{[16,17]}$ another promising anticancer polyketide of lithistid sponge origin. As the main focus of this review, we give an account of our structural assignment work and subsequent efforts to develop an efficient synthesis of this intriguing bioactive macrolide to enable the in vivo evaluation of its antitumour efficacy and SAR studies.

\subsection{Isolation of Leiodermatolide}

Using a manned submersible, sample collections of the lithistid sponge Leiodermatium sp. were made off the coast of Ft. Lauderdale, Florida, and in Wemyss Bight in the Bahamas. Bioassay-guided fractionation of the resulting sponge extracts and extensive chromatographic purification led to the isolation of (-)-leiodermatolide as a colorless powder $(0.0011 \%$ wet weight), corresponding to a unique polyketide chemotype with the assigned planar structure 4 (Figure 2). ${ }^{[16]}$

\subsubsection{Biological Activity of Leiodermatolide}

In their initial patent application, ${ }^{[16]}$ the Harbor Branch group disclosed that leiodermatolide exhibited highly potent antiproliferative activity $\left(\mathrm{IC}_{50}<10 \mathrm{nM}\right)$ against a panel of human cancer cell lines, whilst showing reduced toxicity to normal cells. It was also shown to retain activity in drugresistant cell lines, including those overexpressing the Pglycoprotein efflux pump. Cell-cycle arrest occurred at the G2/M phase, accompanied by abnormal mitotic spindle formation, a characteristic response to anticancer agents that interact with tubulin (e.g. taxol, discodermolide, dictyostatin). ${ }^{[17]}$ The mechanism of action was independently investigated at Pfizer, working with synthetic material made available from the Fürstner group. ${ }^{[18]}$ These studies revealed several unusual, concentration-dependant effects, not previously observed for microtubule-targeting agents. Interestingly, both the Harbor Branch and Pfizer findings indicated that leiodermatolide neither inhibited nor induced the assembly of purified tubulin in vitro, and no evidence for an interaction with tubulin was found. This suggests that it affects microtubule dynamics without directly interacting with tubulin, indicating a novel mechanism of action distinct from that of other known anticancer drugs. It was also suggested that leiodermatolide could be acting as a centrosome-declustering agent but this hypothesis requires verification. Preliminary evaluation in vivo in a mouse model of metastatic pancreatic cancer led to a significant reduction in tumour size, underscoring leiodermatolide's
Figure 1. Structures of the marine-sponge derived antimitotic agents discodermolide (1) and dictyostatin (2), and the designed synthetic hybrid 3. 
clinical potential as a new experimental chemotherapeutic lead for pancreatic and other solid tumours. ${ }^{[19]}$

\subsubsection{Structural Elucidation of Leiodermatolide}

At the outset, extensive NMR spectroscopic analysis performed by the Wright group enabled the determination of the planar structure 4 for (-)-leiodermatolide. The 16membered macrocyclic core contains six stereocentres and is appended with a side chain terminating in a $\delta$-lactone ring bearing three further stereocentres. Notable structural features included the presence of two conjugated dienes, one $(E, E)$ - and one $(Z, Z)$-configured, and a pendant carbamate moiety at $\mathrm{C} 9$.

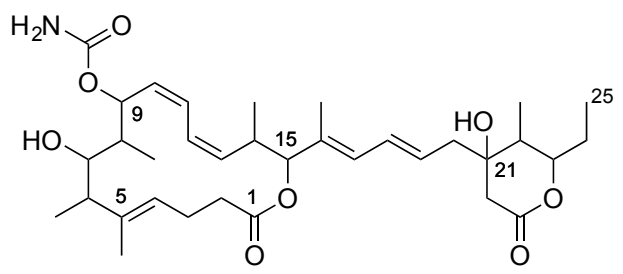

4: leiodermatolide, planar structure 2008

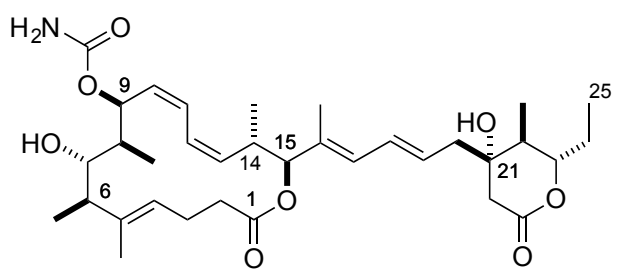

5: (-)-leiodermatolide, 3D structure 2011; wherein the absolute configurations of the macrolactone and $\delta$-lactone regions were arbitrarily assigned

Figure 2. Evolving structural understanding of leiodermatolide.

Following a tentative stereochemical assignment, a precious sample of leiodermatolide was provided for further detailed NMR analysis at Cambridge. ${ }^{[17]}$ Extensive nOe and coupling constant analysis using Murata's method first allowed us to determine the relative configuration of the three isolated stereoclusters at C6-C9, C14-C15 and C21-C25 (Figure 2).

As the distal nature of the two stereoclusters within the macrocyclic core prevented the confident determination of their relative configuration by NMR analysis alone, chemical derivatisation and molecular modelling were employed. The C7,C21-bis-MTPA esters of leiodermatolide were initially prepared in an attempt to determine the absolute configuration by the advanced Mosher's method, however, irregular $\Delta \delta^{S R}$ values meant this approach proved unfruitful. Seeking increased confidence for the assignment of the stereochemistry within the macrocyclic core, we turned to using the computational DP4 GIAO-NMR probability method. ${ }^{[20]}$ The resulting combined ${ }^{1} \mathrm{H}$ and ${ }^{13} \mathrm{C}$ chemical shift correlations on appropriate virtual fragments predicted a single diastereomer with $>99 \%$ probability for the separate macrolactone $(\mathrm{C} 1-\mathrm{C} 15)$ and $\delta$-lactone (C21-C25) rings. Attempts to relate the configuration between these two distinct regions, however, proved inconclusive. Nevertheless, this combined experimental and computational NMR analysis succeeded in reducing the number of stereoisomers to a more manageable four. In 2011, we reported the $3 \mathrm{D}$ representation 5 for $(-)$ leiodermatolide as one of these permutations, which fortuitously turned out to be the correct structural assignment.

At around this time, we embarked on our synthetic campaign to potentially access any of the four candidate structures, in conjunction with performing detailed NMR and chiroptical correlations, as a means of unequivocally determining both the relative and absolute configuration of leiodermatolide.

\subsubsection{Synthetic Efforts Towards Leiodermatolide}

Although lacking detailed knowledge of the stereochemical assignment for leiodermatolide, the Maier group launched their synthetic efforts towards a tentative structure. They first reported a synthesis of several fragments, including a diastereomeric macrocyclic core, epimeric at the two methyl-bearing stereocentres at $\mathrm{C} 8$ and $\mathrm{C} 10$ relative to those assigned in structure 5. ${ }^{[2]}$ In 2016, they subsequently reported the construction of a macrocyclic core with the required revision to the stereochemistry. ${ }^{[22]}$

In 2012, the Fürstner group disclosed a completed synthesis of both candidate diastereomers corresponding to our published structure $\mathbf{5}$ of $(-)$-leiodermatolide. ${ }^{[23]}$ Careful ${ }^{1} \mathrm{H}$ NMR comparison showed that the compound with the diastereomeric side chain was distinguishable by minor differences in peak shape, while the NMR data for 5 exactly matched that obtained for leiodermatolide. Correlation of the optical rotation also confirmed that structure 5 represents the natural enantiomer. Subsequently, the Fürstner group reported an improved synthesis of (-)-leiodermatolide along with further biological results. ${ }^{[18]}$

In 2011, we reported the stereocontrolled synthesis of the macrocyclic core, verifying that our proposed structure and relative configuration for this $\mathrm{C} 1-\mathrm{C} 17$ region were correct. ${ }^{[24]}$ Completion of the synthesis of 5 from this point, however, required modification to our initial strategy. The remainder of this review details these efforts, leading to our successful total synthesis of (-)-leiodermatolide. ${ }^{25]}$

\section{Investigations Culminating in the Cambridge Total Synthesis of (-)- Leiodermatolide}

\subsection{Initial Synthetic Strategy Adopted Towards Leiodermatolide}

At the outset, the key consideration when designing our initial synthetic approach to leiodermatolide was the requirement to be able to access both candidate diastereomers. As outlined in Scheme 1, we arbitrarily targeted the synthesis of ent-5 (the mirror image of our published structure 5) and its diastereomer, where disconnection across the $\mathrm{C} 17-\mathrm{C} 18$ bond served to separate the side chain from the macrocyclic core 6 . We anticipated that the construction of each enantiomer 7 and ent-7 of the C18-C25 fragment containing the $\delta$-lactone ring should be reasonably straightforward (see section 2.1.3). An 


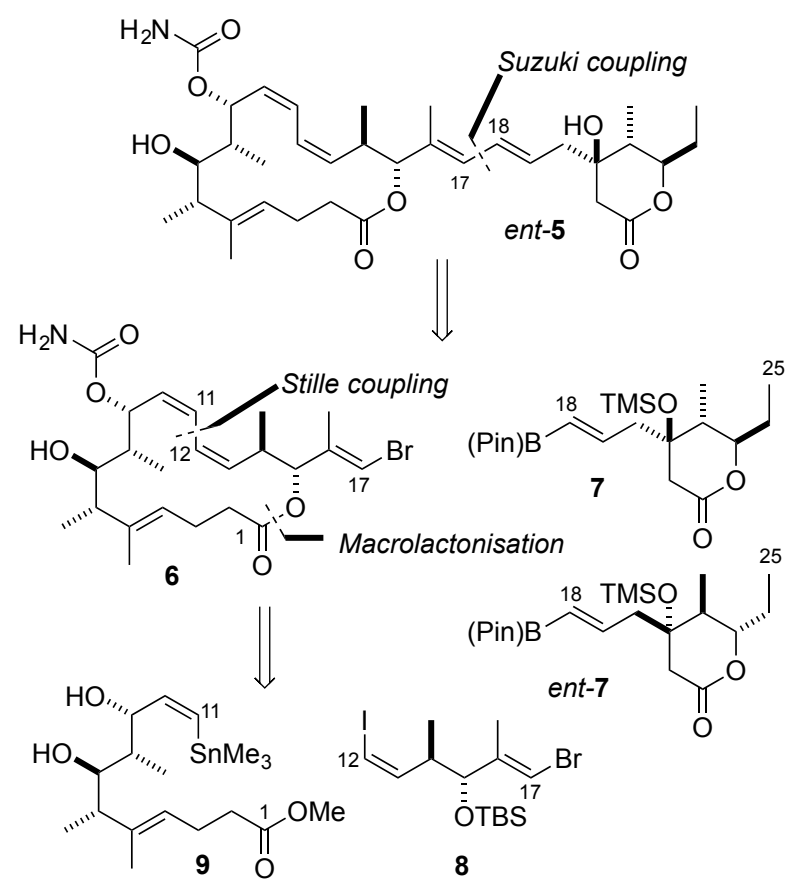

Scheme 1. Synthesis plan for leiodermatolide (ent-5) based on proposed site-specific fragment coupling using the linchpin 8.

adventurous, site-specific, fragment coupling strategy for the stepwise construction of the two conjugated diene moieties was proposed based on the use of the linchpin fragment 8. In detail, it was planned that a Stille crosscoupling between the $\mathrm{C} 1-\mathrm{C} 11$ stannane 9 and the more reactive vinyl iodide at $\mathrm{C} 12$ in $\mathbf{8}$ would initially forge the $(Z, Z)$-diene, followed, after macrolactonisation, by a Suzuki coupling of the remaining bromide at $\mathrm{C} 17$ with the side chain fragment 7 (or ent-7) to install the $(E, E)$-diene.

\subsubsection{Synthetic Studies Directed Towards the Macrocyclic Core Provide Support for the Assigned Stereochemistry}

Following this flexible plan, our synthesis of the macrocyclic core 6 commenced as shown in Scheme 2, with controlled installation of the requisite six stereocentres and four alkenes. A key feature of this route is the efficient introduction of the syn-related $\mathrm{C} 8$ and $\mathrm{C} 9$ stereocentres using chiral ligand-mediated boron aldol methodology developed in our group. ${ }^{[26]}$ To provide a masked $(Z)$-vinyl stannane for the projected Stille cross-coupling step, 3,3dibromoacrolein $\mathbf{1 0}$ served as the aldehyde partner. Using the $(Z)$-selective enolisation of the ethyl ketone 11 (derived from $(S)$-Roche ester) with $((-) \text {-Ipc })_{2} \mathrm{BOTf} /{ }^{i} \operatorname{Pr}_{2} \mathrm{NEt}$, this pivotal aldol addition proceeded with excellent stereocontrol $(>20: 1 \mathrm{dr})$ to afford the syn-adduct 12. An EvansTishchenko reduction ${ }^{[27]}$ of this $\beta$-hydroxy ketone then secured the desired 1,3-anti-diol, again with excellent stereocontrol ( $>20: 1 \mathrm{dr})$. Protection as the bis-TBS ether $\mathbf{1 3}$ required the rather forcing conditions of TBSOTf at $0{ }^{\circ} \mathrm{C}$ to effect the second silylation at $\mathrm{C} 7$, which indicated the feasibility of differentiating the $\mathrm{C} 7$ and $\mathrm{C} 9$ hydroxyl groups. This observation would later have a critical impact on our strategy for the site-selective installation of the carbamate moiety in the endgame.

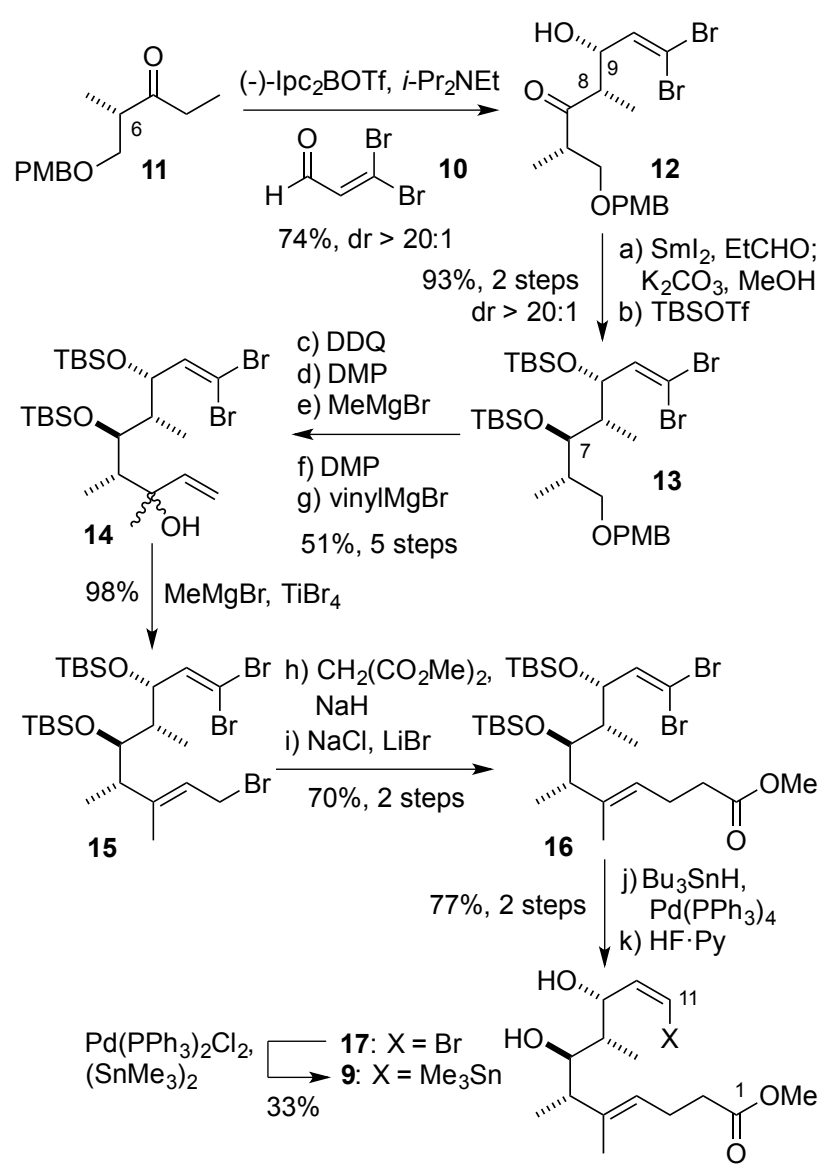

Scheme 2. First-generation synthesis of the $\mathrm{C} 1-\mathrm{C} 11$ fragment 9 of leiodermatolide. $\mathrm{DDQ}=2,3$-dichloro-5,6-dicyano-1,4benzoquinone, $\mathrm{DMP}=$ Dess-Martin periodinane, $\mathrm{Ipc}=$ isopinocampheyl, $\mathrm{Py}=$ pyridine, $\mathrm{TBS}=$ tert-butyldimethylsilyl

Straightforward manipulation progressed $\mathbf{1 3}$ to the tertiary allylic alcohol 14, in preparation for the installation of the trisubstituted double bond and $\mathrm{C} 1$ ester. Whilst the initially explored Claisen rearrangement methodology proceeded with disappointing selectivity, a viable alternative was found in the Lewis acid-mediated rearrangement of allylic alcohols developed by Fuchter. ${ }^{[28]}$ Thus treating the magnesium alkoxide derived from 14 with $\mathrm{TiBr}_{4}$ effected the desired rearrangement, and the resulting allylic bromide 15 was displaced with the anion of dimethylmalonate. Following decarboxylation to give 16, our attention turned to converting the $\mathrm{C} 11$ terminus into the $(Z)$-vinyl stannane. While the controlled semi-reduction of the dibromide to the $(Z)$-vinyl bromide proceeded smoothly under palladiumcatalysed conditions $\left(\mathrm{Bu}_{3} \mathrm{SnH}, \mathrm{Pd}\left(\mathrm{PPh}_{3}\right)_{4}\right)$, subsequent attempts at conversion into the stannane proved unrewarding. After extensive experimentation, a degree of success was achieved by first cleaving the sterically demanding TBS ethers, followed by stannylation under Wulff-Stille conditions $\left(\left(\mathrm{SnMe}_{3}\right)_{2}, \mathrm{Pd}\left(\mathrm{PPh}_{3}\right) \mathrm{Cl}_{2}, \mathrm{Li}_{2} \mathrm{CO}_{3}\right)^{[29]}$ to provide 9 in a disappointing but workable yield. Going forward, this problematic transformation was clearly a bottleneck needing to be addressed in evolving our strategy.

The highly stereocontrolled construction of the C12C17 bis-vinyl halide fragment $\mathbf{8}$ also relied on versatile boron aldol methodology developed in our group (Scheme 3). ${ }^{[30]}$ This commenced with the anti-selective aldol addition between lactate-derived ethyl ketone $\mathbf{1 8}$ and aldehyde 19 which efficiently configured the C14 
and $\mathrm{C} 15$ stereocentres in the resulting adduct $\mathbf{2 0}(>20: 1$ dr). Following silylation of the alcohol and ketone reduction, oxidative glycol cleavage enabled a StorkZhao olefination ${ }^{[31]}$ of the resulting aldehyde to form the desired $(Z)$-vinyl iodide $\mathbf{8}$, in readiness for constructing the macrocyclic core.

In practice, the adventurous Stille coupling of the two fragments 8 and 9 proceeded in the planned sitespecific manner, under the palladium(0)/copper(I) conditions developed by Fürstner $\left(\mathrm{Pd}(\mathrm{PPh})_{3}\right)_{4}, \mathrm{CuTC}$, $\left.\left[\mathrm{Bu}_{4} \mathrm{~N}^{+}\right]\left[\mathrm{Ph}_{2} \mathrm{PO}_{2}^{-}\right]\right),{ }^{[32]}$ to cleanly afford the desired $(Z, Z)$-diene 21. Saponification of the ester and acidmediated desilylation then set the stage for exploring the critical macrolactonisation step on the triol acid $\mathbf{2 2}$. Gratifyingly, this proceeded in excellent yield under Yamaguchi conditions ${ }^{[33]}$ with complete regioselectivity for the desired 16-membered ring in 23. At this stage, our synthetic efforts toward leiodermatolide were making excellent headway, and we did not anticipate the problems waiting ahead!

\subsubsection{Problematic Introduction of the C9-Carbamate and Support for the Assigned Stereochemistry}

On the basis of the observation that the C9 hydroxyl group in intermediate $\mathbf{1 3}$ could be selectively silylated (see section 2.1.1), it was envisaged that the attachment of the carbamate could be achieved at the required C9 position on the macrocycle 23. Disappointingly, treatment of $\mathbf{2 3}$ with trichloroacetyl isocyanate followed by hydrolytic workup $^{[34]}$ provided only a 3:2 mixture of regioisomers, favouring the undesired $\mathrm{C} 7$ carbamate 24. Following chromatographic separation of these isomers, detailed ${ }^{1} \mathrm{H}$ and ${ }^{13} \mathrm{C}$ NMR comparison of the C9 carbamate 6 with leiodermatolide revealed an excellent correlation, lending strong support to our proposed structural assignment for the macrocyclic core. While the NMR correlation supported the assigned relative stereochemistry, the $(+)$-sign of the specific rotation for truncated macrocycle 6 turned out to be opposite to natural (-)-leiodermatolide. Although the structures are different, this result was cautiously taken to suggest that we had possibly started our synthetic efforts in the incorrect enantiomeric series.

\subsubsection{Synthesis and Planned Attachment of the Side Chain Fragment}

In order to gain further evidence for our proposed stereochemical assignment in the $\delta$-lactone ring of the side chain, both epimers of the C21 tertiary alcohol were targeted as shown in Scheme 4. Firstly, the C22 and C23 stereocentres were efficiently installed using a boronmediated aldol reaction of the lactate-derived ketone $(S)$-18 with propionaldehyde to afford $\mathbf{2 5}$, which following an allyl Grignard addition was elaborated into the ketone 26. The two C21 epimers, $\mathbf{2 7}$ and $\mathbf{2 8}$ respectively, could then be selectively accessed either from 26a via an intramolecular Reformatsky reaction or from $\mathbf{2 6} \mathbf{b}$ via an intermolecular Mukaiyama aldol reaction ${ }^{[35]}$ respectively. Detailed NMR comparison of these $\delta$-lactones with the corresponding natural product data showed a good match for 28, in support of our proposed assignment in structure $\mathbf{5}$.

In preparation for the planned side chain attachment to the macrolide core $\mathbf{6}$ via a Suzuki coupling, the alkene of $\mathbf{2 8}$ was elaborated by a Takai-type olefination of the derived aldehyde into the vinyl boronate 7. Disappointingly, the final Suzuki fragment coupling to afford leiodermatolide could not be realised, due to the vinyl bromide in $\mathbf{6}$ proving stubbornly unreactive under the various palladium-catalysed conditions explored.

\subsection{Evolution of the Synthesis Plan}

At this juncture, a revision of our synthetic strategy in Scheme 2 was clearly necessary to overcome the problems encountered in the associated exploratory studies. We first decided to resume work in the enantiomeric series, i.e. now targeting our originally proposed structure 5 in Scheme 5. An essential perturbation was the replacement of the C17 vinyl bromide with a more reactive iodide to help facilitate the attachment of the full side chain. As preliminary studies<smiles>CCC(=O)C(C)O[R16](=O)[O-]</smiles>

Scheme 3. Synthesis of the C12-C17 fragment 8 and its site-specific Stille coupling with $\mathbf{9}$, and progression to the macrocyclic core $\mathbf{6}$. CSA = camphor sulfonic acid, CuTC = copper thiophene-2-carboxylate, DMAP $=4$ (dimethylamino)pyridine, TCBC $=2,4,6$-trichlorobenzoyl chloride 


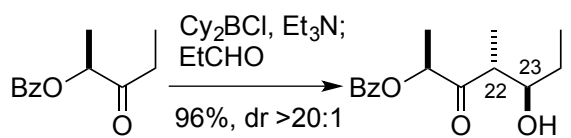

(S)-18

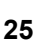

25 [a) TBSOTf]

b) allylMgBr

c) $\mathrm{NaIO}_{4}$
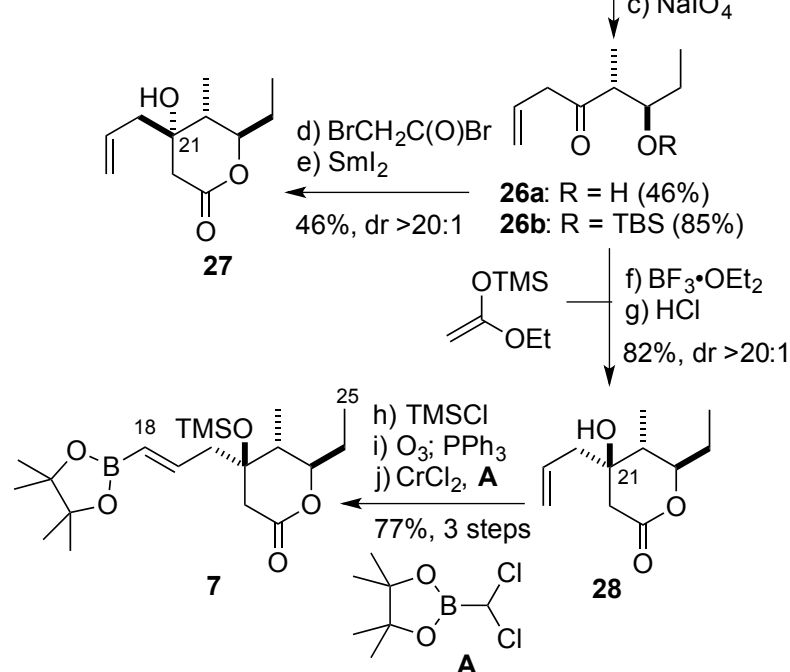

Scheme 4. Synthesis of the side chain fragment 7. TMS = trimethylsilyl

of the Stille cross-coupling reaction on the bis-vinyl iodide analogue of fragment $\mathbf{8}$ resulted in little or no regioselectivity, a bis-halide linchpin was no longer considered a viable option. Our fragment coupling strategy was thus revised to employ a suitable C13-C17 fragment 29 to assemble the full side chain containing the $\delta$-lactone, prior to installation of the $\mathrm{C} 12$ vinyl iodide in $\mathbf{3 0}$ and its Stille coupling with the $\mathrm{C} 1-\mathrm{C} 11$ fragment 31 . This would make our proposed route more convergent overall while lengthening the reaction sequence that might need to be repeated in order to attach both diastereomeric side chains. Despite the initially unpromising results, it was decided to persist with installing the $\mathrm{C} 9$ carbamate at a late stage on the undifferentiated 1,3-diol 32. It was felt that this regioselectivity problem could be overcome and that the endgame would be simplified by the avoidance of additional protecting group manipulations. The two issues with the synthesis of the original $\mathrm{C} 1-\mathrm{C} 11$ fragment 9 were the low yielding installation of the vinyl stannane and the number of steps required to introduce the trisubstituted alkene. An entirely new strategy to construct the revised $\mathrm{C} 1-\mathrm{C} 11$ fragment $\mathbf{3 1}$ was thus pursued in an attempt to improve these matters.

\subsubsection{A Revised Approach to the C1-C11 Fragment}

The resulting second-generation synthesis of the western fragment starts out with the Roche ester-derived Weinreb amide 33 (Scheme 6), which was elaborated by a Grignard addition into the ketone 34 . The trisubstituted double bond was constructed via controlled enolisation of ketone $\mathbf{3 4}$ with LiHMDS before trapping with Comins' reagent ${ }^{[36]}$ to form the $(E)$-vinyl triflate 35. After extensive optimisation, the best conditions for installation of the methyl group were found to be Suzuki coupling of $\mathbf{3 5}$ using trimethyl boroxine. ${ }^{[37]}$ Manipulation of $\mathbf{3 6}$ to the aldehyde $\mathbf{3 7}$ then set

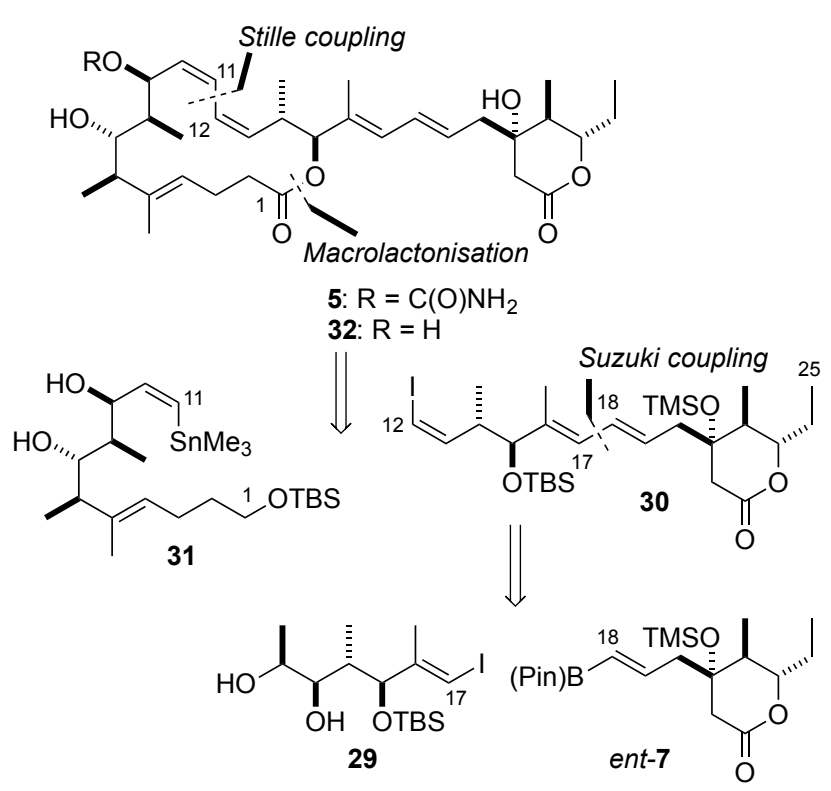

Scheme 5. Revised synthesis plan for leiodermatolide (5).

the stage for a boron-mediated anti-aldol addition with the lactate-derived ethyl ketone $(R)$-18. Notably, this marked the third application of this versatile chiral ketone in our leiodermatolide synthesis, affording adduct $\mathbf{3 8}$ with excellent control over the installation of the $\mathrm{C} 7$ and $\mathrm{C} 8$ stereocentres $(96 \%,>20: 1 \mathrm{dr})$. To introduce the remaining C9 stereocentre, the $\beta$-hydroxy ketone $\mathbf{3 8}$ was next elaborated into the ynone 39. Both the Evans-Tischenko ${ }^{[27]}$ and Evans-Saksena ${ }^{[38]}$ protocols for 1,3-anti reduction were ineffective with this substrate. The former yielded the products of a retro-aldol-aldol-Tischenko pathway, ${ }^{[39]}$ while the latter conditions led to poor stereocontrol. It was proposed that this was due to the small size of the alkyne substituent, reducing its preference to occupy an equatorial position in the transition state. The logical way forward was to first effect the conversion of the alkyne to the larger $(Z)$ vinyl iodide to improve the stereocontrol in the reduction step. Kishi's procedure for conjugate addition of an iodide nucleophile to an ynone under acidic conditions proved rewarding, preferentially leading to the desired $(Z)$-vinyl iodide 40. ${ }^{[40]}$ Gratifyingly, the Evans-Saksena reduction now afforded exclusively the desired 1,3-anti diol 41. Conversion to the vinyl stannane was then achieved by lithiation and trapping with tributyltin chloride, with or without acetonide protection of the diol moiety. This afforded the desired $\mathrm{C} 1-$ C11 fragments $\mathbf{3 1}$ and $\mathbf{4 2}$ in a significantly improved yield over the first-generation approach $(20 \%$ yield over 14 steps for 42 vs $6 \%$ yield over 14 steps for 9 ).

\subsubsection{Second-Generation Fragment Coupling Sequence}

The existing routes to the $\mathrm{C} 12-\mathrm{C} 17$ and $\mathrm{C} 18-\mathrm{C} 25$ fragments previously used to access the macrocyclic core 6 were adapted based on experience, as shown in Scheme 7. The vinyl bromide in aldehyde $\mathbf{1 9}$ was replaced with a more reactive iodide, as discussed in section 2.2. During model studies into formation of the $\mathrm{C} 17-\mathrm{C} 18$ bond, the TES ether at $\mathrm{C} 15$ had been observed to be partially labile under the basic conditions required for Suzuki coupling and so this 


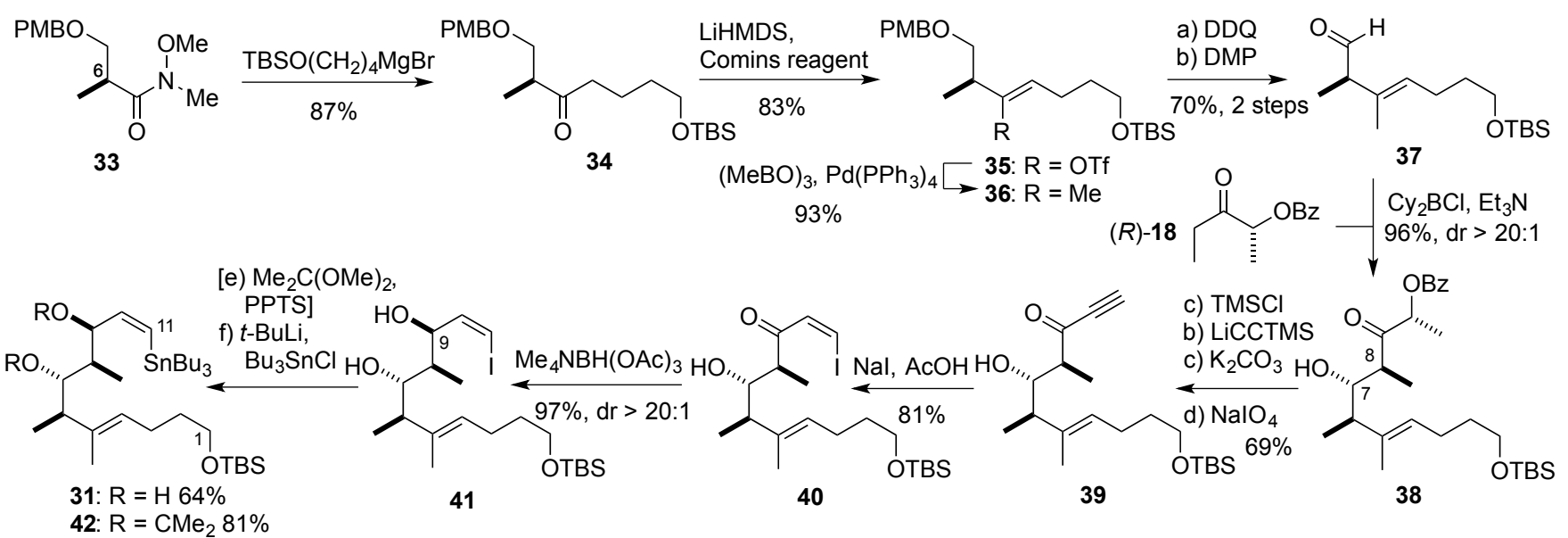

Scheme 6. Improved synthesis of the $\mathrm{C} 1-\mathrm{C} 11$ fragment 42. Comins reagent $=2-\left(\mathrm{Tf}_{2} \mathrm{~N}\right)-5-\mathrm{Cl}\left(\mathrm{C}_{3} \mathrm{H}_{3} \mathrm{~N}\right)$, $\mathrm{LiHMDS}=$ lithium hexamethyldisilylazide

was replaced with a more robust TBS group in 29. While the anticipated Suzuki coupling between 29 and ent-7 proceeded smoothly under thallium-mediated conditions, it was proposed that several functional group manipulations could be avoided by employing a Heck reaction instead. This was explored with 29 and 43 , and an efficient Heck coupling procedure ${ }^{[41]}$ using $\mathrm{Pd}(\mathrm{OAc})_{2}$ and $\mathrm{Ag}_{2} \mathrm{CO}_{3}$ was successfully developed that cleanly afforded the $(E, E)$-diene 44 . The terminal diol in 44 was then elaborated into the $(Z)$-vinyl iodide $\mathbf{3 0}$ again using a Stork-Zhao olefination, ${ }^{[31]}$ in readiness for the key Stille cross-coupling with the (Z)-vinyl stannane $\mathbf{3 1}$ or 42. As shown in Scheme 8 , this pivotal step proceeded smoothly to unite the two halves of the carbon backbone to generate the requisite $(Z, Z)$-dienes 45 and $\mathbf{4 6}$. The originally devised endgame called for the C7 and C9 alcohols to remain unprotected and thus required a challenging selective oxidation in order to obtain the correct oxidation level at $\mathrm{C} 1$ for macrolactonisation. In practice, this proved unsuccessful and necessitated a minor revision of the strategy, employing the acetonide 46 instead. The oxidations at $\mathrm{C} 1$ were successfully effected and removal of the C15 TBS ether revealed the leiodermatolide seco-acid 47. Macrocyclisation proceeded smoothly under Yamaguchi conditions to engage the $\mathrm{C} 15$ alcohol and the acetonide was then cleaved to reveal 32, as the putative precursor to leiodermatolide

\subsubsection{Completion of the Cambridge Total Synthesis of (- )-Leiodermatolide: Attachment of the C9 Carbamate}

A key aspect of our strategy was the absence of differential protection of the $\mathrm{C} 7$ and $\mathrm{C} 9$ hydroxyl groups. Completion of the leiodermatolide synthesis thus hinged on achieving the site-selective formation of the requisite carbamate at $\mathrm{C}$. From molecular modelling, the allylic nature of the C9 position in $\mathbf{3 2}$ compared to the doubly $\alpha$-branched $\mathrm{C} 7$ position suggested it was less sterically hindered and potentially more reactive to derivatisation. As with the previously prepared truncate $\mathbf{2 3}$ discussed in section 2.1.2, however, treatment with trichloroacetyl isocyanate disappointingly led to a mixture of regioisomers, again favouring the undesired carbamate. Much effort went into attempting to overturn this undesired selectivity but without success. Frustratingly, it was noted that conventional esterification and silylation reactions, along with formation of the dimethylcarbamate using the carbamoyl chloride, all proceeded with pronounced selectivity for the desired C9 position.

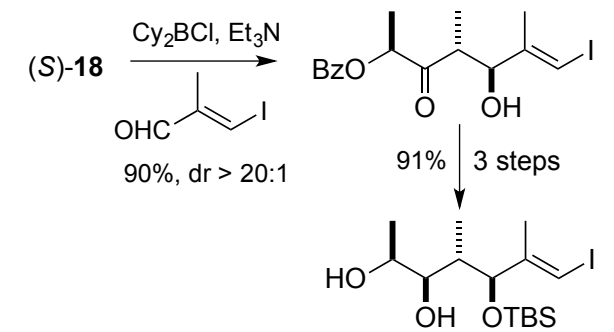

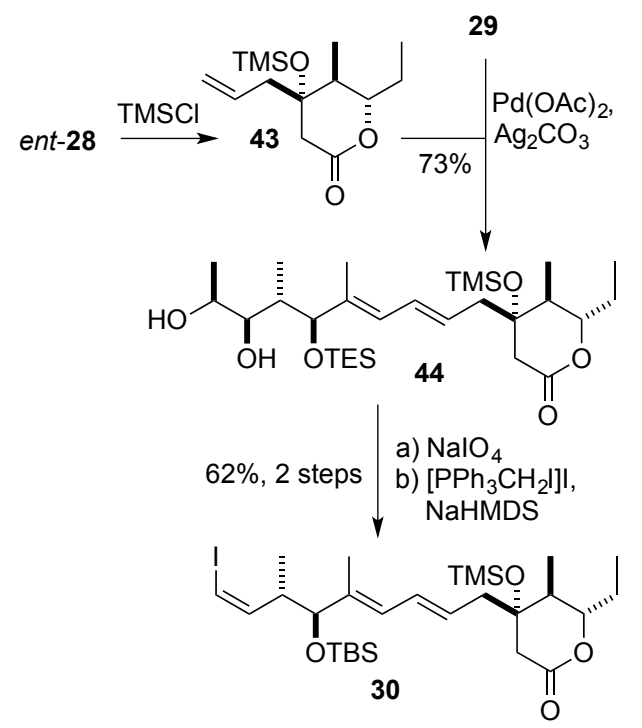

Scheme 7. Synthesis of revised $\mathrm{C} 13-\mathrm{C} 17$ fragment 29 and Heck coupling with $\mathbf{4 3}$ to construct the $(E, E)$-diene in $\mathbf{3 0}$.

This indication that the C9 alcohol was indeed the more reactive position in the substrate $\mathbf{3 2}$ and that the 
isocyanate reagent was behaving anomalously pointed us towards a solution to the problem. Silylation of both alcohols in $\mathbf{3 2}$ could be achieved using trimethylsilyl imidazole and the C9 silyl ether was then selectively cleaved under mildly acidic conditions (PPTS, MeOH). Gratifyingly, carbamate formation on treatment with with trichloroacetyl isocyanate and acidic removal of the remaining TMS ether at C7 then afforded only (-)leiodermatolide (5). To our satisfaction, all NMR and chiroptical data for this synthetic material correlated with those already recorded for the natural sample of ()-leiodermatolide provided by Amy Wright.

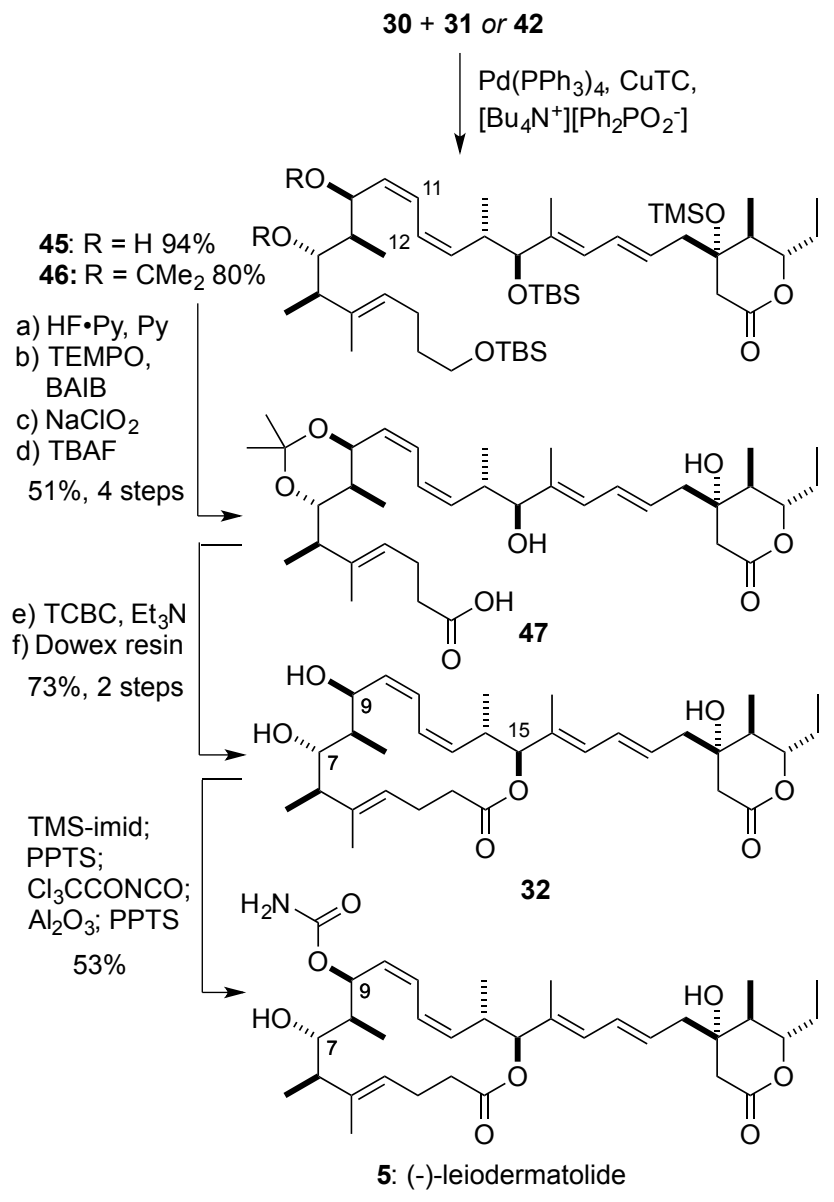

Scheme 8. Stille coupling of fragments 30 and $\mathbf{4 2}$, followed by macrolactonisation and elaboration into (-)-leiodermatolide (5). $\mathrm{BAIB}=$ bis(acetoxy)iodobenzene, $\mathrm{PPTS}=$ pyridinium paratoluenesulfonate, TBAF = tetrabutylammonium fluoride, TEMPO = 2,2,6,6-tetramethylpiperidine 1-oxyl

\section{Summary}

Our successful total synthesis of (-)-leiodermatolide ${ }^{[25]}$ provided further verification of the assigned 3D structure $\mathbf{5}$. While our initial studies towards the construction of the leiodermatolide macrocycle and side chain provided strong support for the relative configuration proposed in $\mathbf{5}$, this plan proved to be unsuitable for achieving the total synthesis itself. Evolution of our strategy with judicious revisions to the fragment couplings and a redesigned synthesis of the C1-C11 fragment addressed these problems, and led to the highly convergent assembly of the leiodermatolide backbone. While the regioselective carbamate installation in the endgame initially proved problematic, it was ultimately solved leading to completion of the total synthesis of (-)leiodermatolide in 23 steps LLS and $3.2 \%$ overall yield. Notably, every element of $\mathrm{sp}^{3}$ and $\mathrm{sp}^{2}$ stereochemistry is efficiently controlled with $>20: 1$ selectivity, with a minor exception being the installation of the $\Delta^{10,11}$ alkene $(10: 1$ $Z / E)$.

In conclusion, the marine macrolide leiodermatolide stands out as an excellent example of how a combination of experimental and computational NMR analysis, together with chemical synthesis, can be used to achieve the complete structural assignment of biologically important natural products. Inevitably, NMR analysis takes the minority of the time and reveals the majority of the structural information but relies on synthetic efforts to fill in the gaps. Going forward, the development of a practical total synthesis of leiodermatolide should enable access to both a sustainable supply and designed analogs for further evaluation of this promising new experimental antimitotic drug in cancer chemotherapy. ${ }^{[19,42]}$

\section{Acknowledgements}

We thank the EPSRC UK National Mass Spectrometry Facility (NMSF) at Swansea University and Prof. David Spring (Cambridge) for support. The work summarised in this review was ably performed by the leiodermatolide team at Cambridge who are named in the appropriate references (K. K.-H. Ng, S. M. Dalby, D. C. Millican, G. J. Naylor, T. Paquet, S. Williams), whose dedication, hard work and contributions to the project as a whole are gratefully acknowledged. We especially thank Prof. Amy Wright (HBOI, Florida Atlantic University) for providing an authentic sample of natural leiodermatolide and helpful discussions.

\section{References}

[1] a) I. Paterson, E. A. Anderson, Science 2005, 310, 451; b) K.-S. Yeung, I. Paterson, Chem. Rev. 2005, 105, 4237; c) S. M. Dalby, I. Paterson, Curr. Opin. Drug Discov. Devel. 2010, 13, 777; d) P. L. Winder, S. A. Pomponi, A. E. Wright, A. Mar. Drugs 2011, 9, 2643; e) W. H. Gerwick, A. M. Fenner, Microb. Ecol. 2013, 65, 800; f) K. von Schwarzenberg, A. M. Vollmar, Cancer Lett. 2013, 332, 295; g) D. J. Newman, G. M. Cragg, J. Nat. Prod. 2016, 79, 629.

[2] a) W. H. Gerwick, B. S. Moore, Chem. Biol. 2012, 19, 85; b) A. Martins, H. Vieira, H. Gaspar, S. Santos, Mar. Drugs 2014, 12, 1066; c) D. J. Newman, G. M. Cragg, Planta Medica 2016, 82, 775 .

[3] a) B. K. S. Yeung, Curr. Opin. Chem. Biol. 2011, 15, 523; b) B.-F. Ruan, H.-L. Zhu, Curr. Med. Chem. 2012, 19, 2652.

[4] a) G. R. Pettit, Y. Kamano, C. L. Herald, A. A. Tuinman, F. E. Boettner H. Kizu, J. M. Schmidt, L. Baczynskyj, K. B. Tomer, R. J. Bontemps J. Am. Chem. Soc. 1987, 109, 6883; b) G. R. Pettit, Y. Kamano, C. L. Herald, Y. Fujii, H. Kizu, M. R. Boyd, F. E. Boettner, D. L. Doubek, J. M. Schmidt, J. C. Chapuis, C. Michel, Tetrahedron 1993, 49, 9151.

[5] a) J. A. Francisco, C. G. Cerveny, D. L. Meyer, B. J. Mixan, K. Klussman, D. F. Chase, S. X. Rejniak, K. A. Gordon, R. DeBlanc, B. E. Toki, C. L. Law, S. O. Doronina, C. B. Siegall, P. D. Senter, A. F. Wahl, Blood 2003, 102, 1458; b) P. D. 
Senter, E. L. Sievers, Nat. Biotechnol. 2012, 30, 631.

[6] a) I. Paterson, G. J. Florence, K. Gerlach, J. P. Scott, Angew. Chem. 2000, 112, 385; Angew. Chem. Int. Ed. Engl. 2000, 39, 377; b) I. Paterson, G. J. Florence, K. Gerlach, J. P. Scott, N. Sereinig, J. Am. Chem. Soc. 2001, 123, 9535; c) I. Paterson, O. Delgado, G. J. Florence, I. Lyothier, J. P. Scott, N. Sereinig, Org. Lett. 2003, 5, 35; d) I. Paterson, G. J. Florence, Eur. J. Org. Chem. 2003, 2193.

[7] S. P. Gunasekera, M. Gunasekera, R. E. Longley, G. K. Schulte, J. Org. Chem. 1990, 55, 4912.

[8] A. B. Smith, III, M. D. Kaufman, T. J. Beauchamp, M. J. LaMarche, H. Arimoto, Org. Lett. 1999, 1, 1823.

[9] S. J. Mickel, D. Niederer, R. Daeffler, A. Osmani, E. Kuesters, E. Scmid, K. Schaer, R. Gamboni, W. Chen, E. Loser, F. R. Kinder, K. Konigsberger, K. Prasad, T. M. Ramsey, G. F. Florence, I. Lyothier, I. Paterson, Org. Process Res. Dev. 2004, 8,122 ; and the preceding four papers.

[10] R. A. Isbrucker, J. Cummins, S. A. Pomponi, R. E. Longley, A. E. Wright, Biochem. Pharmacol. 2003, 66, 75.

[11] G. R. Pettit, Z. A. Cichacz, F. Gao, M. R. Boyd, J. M. Schmidt, J. Chem. Soc. Chem. Commun. 1994, 1111.

[12] I. Paterson, R. Britton, O. Delgado, A. E. Wright, Chem. Commun. 2004, 632.

[13] I. Paterson, R. Britton, O. Delgado, A. Meyer, K. G. Poullennec, Angew. Chem. 2004, 116, 4729; Angew. Chemie Int. Ed. 2004, 43, 4629.

[14] Y. Shin, J.-H. Fournier, Y. Fukui, A. M. Brückner, D. P. Curran, Angew. Chem. 2004, 116, 4734; Angew. Chemie Int. Ed. 2004, 43, 4634.

[15] a) I. Paterson, G. J. Naylor, A. E. Wright, A. Chem. Commun. 2008, 4628; b) G. J. Florence, N. M. Gardner, I. Paterson, Nat. Prod. Rep. 2008, 25, 342; c) I. Paterson, G. J. Naylor, N. M. Gardner, E. Guzman, A. E. Wright, Chem. Asian J. 2011, 6, 459.

[16] A. E. Wright, J. K. Reed, J. Roberts, R. E. Longley, U.S. Pat. Appl. Publ. (USA), US2008033035, 14 pp. [Chem. Abstr. 2008 , 148, 230103].

[17] I. Paterson, S. M. Dalby, J. C. Roberts, G. J. Naylor, E. A. Guzman, R. Isbrucker, T. P. Pitts, P. Linley, D. Divlianska, J. K. Reed, A. E. Wright, Angew. Chem. 2011, 123, 3277; Angew. Chem. Int. Ed. Engl. 2011, 50, 3219.

[18] D. Mailhol, J. Willwacher, N. Kausch-Busies, E. E. Rubitski, Z. Sobol, M. Schuler, M. H. Lam, S. Musto, F. Loganzo, A. Maderna, A. Fürstner, J. Am. Chem. Soc. 2014, 136, 15719.

[19] E. A. Guzman, Q. Xu, T. P. Pitts, K. O. Mitsuhashi, C. Baker, P. A. Linley, J. Oestreicher, K. Tendyke, P. L. Winder, E. M. Suh, A. E. Wright, Int. J. Cancer 2016, 139, 2116.

[20] a) S. G. Smith, J. M. Goodman, J. Am. Chem. Soc. 2010, 132, 12946; b) C. I. MacGregor, B. Y. Han, J. M. Goodman, I. Paterson, Chem. Commun. 2016, 52, 4632.

[21] a) V. Navickas, C. Rink, M. Maier, Synlett 2011, 191; b) C. Rink, V. Navickas, M. E. Maier, Org. Lett. 2011, 13, 2334.

[22] A. Reiss, M. E. Maier, Org. Lett. 2016, 18, 3416.

[23] J. Willwacher, N. Kausch-Busies, A. Fürstner, A. Angew. Chem. 2012, 124, 12207; Angew. Chem. Int. Ed. Engl. 2012, $51,12041$.

[24] I. Paterson, T. Paquet, S. M. Dalby, Org. Lett. 2011, 13, 4398.

[25] I. Paterson, K. K.-H. Ng, S. Williams, D. C. Millican, S. M. Dalby, Angew. Chem. 2014, 126, 2730; Angew. Chem. Int. Ed.
Engl. 2014, 53, 2692.

[26] a) I. Paterson, M. A. Lister, Tetrahedron Lett. 1988, 29, 585; b) I. Paterson, J. M. Goodman, M. A. Lister, R. C. Schumann, C. K. McClure, Tetrahedron 1990, 46, 4663; c) Paterson, I.; Norcross, R. D.; Ward, R. A.; Romea, P.; Lister, M. A. J. Am. Chem. Soc. 1994, 116, 11287; d) I. Paterson, R. M. Oballa, Tetrahedron Lett. 1997, 47, 8241; e) I. Paterson, D. J. Wallace, K. R. Gibson Tetrahedron Lett. 1997, 38, 8911; f) I. Paterson, M. Donghi, K. Gerlach, Angew. Chem. 2000, 112, 3453; Angew. Chem. Int. Ed. Engl. 2000, 39, 12041; g) I. Paterson, M. P. Housden, C. J. Cordier, P. M. Burton, F. A. Mühlthau, I. Paterson, Org. Biomol. Chem. 2015, 13, 5716.

[27] D. A. Evans, A. H. Hoveyda, J. Am. Chem. Soc. 1990, 112, 6447.

[28] M. J. Fuchter, J.-N. Levy, Org. Lett. 2008, 10, 4919.

[29] W. D. Wulff, G. A. Peterson, W. E. Bauta, K.-S. Chan, K. L. Faron, S. R. Gilbertson, R. W. Kaesler, D. C. Yang, C. K. Murray, J. Org. Chem. 1986, 51, 277.

[30] a) I. Paterson, D. J. Wallace, S. M. Velázquez, Tetrahedron Lett. 1994, 35, 9083; b) I. Paterson, D. J. Wallace, Tetrahedron Lett. 1994, 35, 9083; c) I. Paterson, D. J. Wallace, K. R. Gibson, Synthesis 1998, 639.

[31] G. Stork, K. Zhao, Tetrahedron Lett. 1989, 30, 2173.

[32] A. Fürstner, J.-A. Funel, M. Tremblay, L. C. Bouchez, C. Nevado, M. Waser, J. Ackerstaff, C. C. Stimson, Chem. Commun. 2008, 2873.

[33] J. Inanaga, K. Hirata, H. Saeki, T. Katsuki, Y. Yamaguchi, Bull. Chem. Soc. Jpn. 1979, 52, 1989.

[34] P. Kočovský, Tetrahedron Lett. 1986, 27, 5521.

[35] a) T. Mukaiyama, K. Banno, K. Narasaka, J. Am. Chem. Soc. 1974, 96, 7503; b) S. B. J. Kan, K. K.-H. Ng, I. Paterson, Angew. Chem. 2013, 52, 9267; Angew. Chem. Int. Ed. Engl. 2013, 52, 9097.

[36] D. L. Comins, A. Dehghani, Tetrahedron Lett. 1992, 33, 6299.

[37] M. Gray, I. P. Andrews, D. F. Hook, J. Kitteringham, M. Voyle, Tetrahedron Lett. 2000, 41, 6237.

[38] D. A. Evans, K. T. Chapman, E. M. Carreira, J. Am. Chem. Soc. 1988, 110, 3560 .

[39] P. D. Dorgan, J. Durrani, M. J. Cases-Thomas, A. N. Hulme, J. Org. Chem. 2010, 75, 7475.

[40] M. Taniguchi, S. Kobayashi, M. Nakagawa, T. Hino, Y. Kishi, Tetrahedron Lett. 1986, 27, 4763.

[41] T. Jeffery, J. Chem. Soc. Chem. Commun. 1991, 324.

[42] For leading references to recent syntheses of other anticancer macrolides by our group, see: a) S. M. Dalby, J. GoodwinTindall, I. Paterson, Angew. Chem. 2013, 125, 6645; Angew. Chem. Int. Ed. Engl. 2013, 52, 6517; b) I. Paterson, S. J. Fink, L. Y. W. Lee, S. J. Atkinson, S. B. Blakey, Org. Lett. 2013, 15, 3118; c) I. Paterson, P. Maltas, S. M. Dalby, J. H. Lim, E. A. Anderson, Angew. Chem. 2012, 124, 2803; Angew. Chem. Int. Ed. Engl. 2012, 51, 2749.

Received: ((will be filled in by the editorial staff)) Accepted: ((will be filled in by the editorial staff)) Published online: ((will be filled in by the editorial staff)) 
